ISAHP 2003, Bali, Indonesia, August 7-9, 2003

\title{
HR DEVELOPMENT STRATEGY THROUGH COMPETENCY PROFILE ANALYSIS IN WIJAYA KARYA (LIMITED)
}

\author{
Kumala I. Suryo and Kirti Peniwati \\ PPM Graduate School of Management \\ J1. Menteng Raya 9, Jakarta 10340, Indonesia \\ kumalasuryo@yahoo.com; Kirti@indo.net.id
}

\begin{abstract}
Wijaya Karya (Limited), usually called by its abbreviation WIKA, is an Indonesian state company with 700 employees and four business pillars i.e., construction, manufacturing, trade, and realty. Entering the $21^{\text {st }}$ century, WIKA has been striving for increasing organization flexibility to satisfy their customers better. The company needs to ensure that its people are more innovative, technology literate, and customer oriented. They need not only to possess the required skills and knowledge but also to demonstrate behaviors consistent with company values. WIKA management is convinced that competence based human resource strategy would lead to the success of the company.
\end{abstract}

The object of this paper is to present an AHP model for WIKA competence based HR management, providing:

- $\quad$ a structured model of HR competency mix;

- $\quad$ a measurement system to assess level of competency demonstrated by each employee;

- $\quad$ a system that could guide prioritizing and planning for HR competency development.

The AHP model is structured as follows:

- Level 0: The goal of To be an excellent company in Engineering and Construction Industry in South East Asia.

- Level 1: WIKA's perspectives, i.e., financial, external, internal, innovation, people.

- Level 2: Competency clusters, i.e., quality, relationship, individual effectiveness, managerial, and know-How.

- Level 3: Sets of WIKA's competency requirements (17 items).

- Level 4: Level of demonstrated competence (LD), ranges from no opportunity to always.

Relative priority of the set of competencies is different for each employee rank. In this paper, the process is illustrated with two distinct employee ranks. Once the set of competency requirements are defined, they need to be communicated such that:

- Employees could assess themselves \& they will know what competencies should be demonstrated more

- Management could arrange the development plan proportionally

Implementation begins with individual assessment to obtain employee competency profiles. Profiles of hypothetical employees from the two ranks used as illustration are provided. A composite score for each employee can be obtained, indicating his or her ranking relative to the other employees. The next step is identifying needs for development by determining what kinds of competence to develop and up to what level. It is proposed that certain employees are used as benchmarks for identifying development effort needed. An employee who is judged as showing superior performance and always demonstrated a particular competency may be selected as a benchmark for that competency. 
